\title{
Repurposing closure cost estimation tools: a Gold Fields case study of the benefit of integration
}

\author{
R Getty SRK Consulting (Australasia) Pty Ltd, Australia \\ D Caporn Gold Fields Ltd, Australia \\ D Kyan SRK Consulting (Australasia) Pty Ltd, Australia \\ J Beltran SRK Consulting (Australasia) Pty Ltd, Australia
}

\begin{abstract}
Closure cost estimation tools such as the publicly available Standardized Reclamation Cost Estimator (SRCE) are widely used to determine closure cost estimates for a variety of purposes. The SRCE was developed to provide a robust, defensible calculator for mine closure financial assurance by the State of Nevada, USA, and has been used internationally for financial assurance (FA) cost estimates, life-of-mine (LOM) and provision for environmental rehabilitation (PER), and for internal closure cost estimates.

Minimising the liability of closure costs is increasingly important for mine planners, as experience dealing with mature mine sites has led to a better understanding of the magnitude of actual closure costs, and as companies seek to reduce ongoing liabilities associated with unrehabilitated land. In this context, Gold Fields $L t d$ has been working with the added functionality of the revised SRCE (v2.0) in relation to its St Ives operations to repurpose the closure cost model to facilitate real-time planning and management of mine closure. Specifically, the flexibility of the SRCE has been used at St Ives to analyse closure options. This has provided the benefit of reducing long-term closure costs by adapting short-term mine plans to accommodate the extended view of the mine life.
\end{abstract}

Keywords: Standardized Reclamation Cost Estimator, cost estimate, repurpose, planning, budgeting tool

\section{Introduction}

At the First International Seminar on Mine Closure in 2006, five papers addressed the topic of closure cost estimation (Dodd et al. 2006; Drebenstedt 2006; Pierce \& Wen 2006; Watson 2006; Wiid 2006) and the importance of realistic and defensible closure cost estimation is still very relevant 13 years later. Historically inadequate closure cost estimates have left liabilities to be dealt with by the government and community. Early recognition of closure costs allows realistic asset valuations, integration of mine closure into mine lifecycle planning, enables progressive budgeting and scheduling of closure activities, and reduces closure risks in line with international best practice (Department of Industry, Innovation and Science (DIIS) 2016; Department of Industry, Innovation and Science (ICMM) 2019). International industry best practice recognises that mine closure planning should commence early, be fully integrated into the business model and mine plan, become progressively more refined as more information is obtained during operations, be adaptive with ongoing review and contain a level of financial detail that becomes more accurate as more information is obtained (Nehring \& Cheng 2016; Morrison-Saunders et al. 2016; DIIS 2016; ICMM 2019).

Closure cost estimates can be developed for many purposes including due diligence, bankable feasibility, stock exchange reporting, government assurances, life-of-mine (LOM) plans, provision for environmental rehabilitation (PER) or sudden closure, and internal company accounting. The Mine Closure Checklist for Governments policy guidance recommends that mines establish credible, auditable estimates of closure costs and a financial assurance system that incentivises operators to close mines in a timely manner (APEC Mining Task Force 2018, p. 10). Financial assurance requirements vary between jurisdictions with some requiring the use of purpose-built closure cost estimation tools and estimates of financial liability which must comply with 
accounting obligations, such as the International Financial Reporting Standards (IFRS), and the reporting principles of local legislation and the relevant stock exchange. These closure cost estimate tools must therefore be able to accept variable inputs, as each mine is specific in its design and closure obligations, and be auditable, defensible and tamper proof.

One such closure cost estimation tool is the Standardized Reclamation Cost Estimator (SRCE) (see http://nvbond.org/about). The SRCE model was originally developed for the Nevada Standardized Unit Cost Project in 2006 and was based on the regulatory requirements of the U.S. Department of Interior, Bureau of Land Management (BLM) and the Nevada Division of Environmental Protection (NDEP). The SRCE model meets IFRS IAS 37 for Provisions, Contingent Liabilities and Contingent Assets and uses first principle methods that closely mirror good international best practice and have been accepted in many international jurisdictions and by financial auditors. The SRCE model is primarily used for LOM, PER and financial assurance closure cost estimates. SRK was integral to the initial development of the SRCE and has been part of its ongoing development.

Western Australia (WA) is the second most attractive jurisdiction in the world for mining investment when considering mineral and policy perception according to the Fraser Institute Annual Report (Steadman \& Green 2018). The Guidelines for Preparing Mine Closure Plans (Western Australian Environmental Protection Authority 2015) which define the legislative requirements for mine closure in WA require that a Mine Closure Plan (MCP) is updated and approved at a minimum of every three years. The MCP must include a transparent and verifiable mine closure cost methodology which is not prescribed.

The St Ives gold mine (St Ives) is owned by Gold Fields Ltd and is located about $70 \mathrm{~km}$ south of Kalgoorlie and about $630 \mathrm{~km}$ east of Perth (Figure 1). Gold Field's tenure at St Ives covers about 42,600 ha and mining is carried out by both open cut and underground methods over 19 satellite mining areas and seven areas defined for tailings management, contractor areas and exploration causeways. Mining operations commenced in 1981, although sporadic small-scale mining had occurred since 1919. Therefore, St Ives has areas in various states of rehabilitation completion. In addition to the satellite mines and associated waste dumps, St Ives has numerous water management, infrastructure, and administration areas as well as processing and transport facilities.

In 2015, a need was identified to refine the budgeting and scheduling of mine closure costs to ensure that sufficient provision was in place to meet the commitments made in the MCP. Gold Fields had been using the SRCE for annual internal company accounting of mine closure costs since 2016. Closure cost estimates are audited internally each year and externally by internationally recognised auditors every three years and certified against financial requirements. Gold Fields identified an opportunity to utilise the built-in functionality of SRCE to efficiently integrate scheduled mine closure costs into the mine plan and ongoing mine operations. The integrated workflow is described later.

\section{Methodology}

The first stage to developing a more refined budgeting and scheduling tool for mine closure was to align individual mine closure tasks with the locations and features of the MCP and with Gold Fields accounting codes. The functionality of the SRCE model has been integrated with the Rehabilitation Management System (RMS) developed by Gold Fields (2011) to standardise the rehabilitation workflow across the site. The SRCE model is used in the planning and budgeting of scheduled rehabilitation as well as annual internal financial provisioning. 


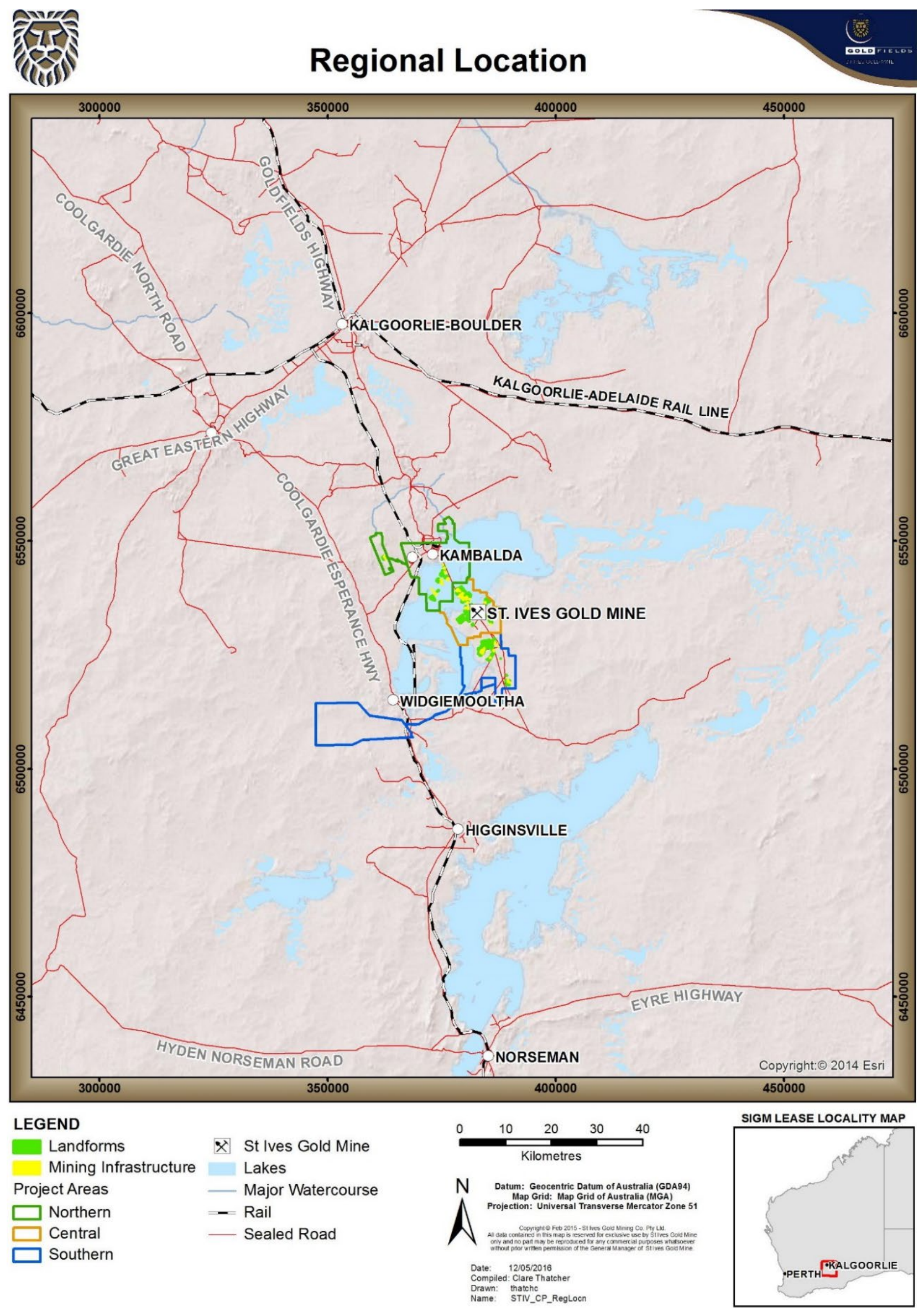

Figure 1 Location of the St Ives Gold Mine 


\subsection{Standardized Reclamation Cost Estimator model}

The SRCE model is Excel based software that uses first principles to calculate volumes, distances and productivities to build a cost estimate for closure works. Physical attributes such as slope, height, underlying ground level and site-specific closure prescriptions such as topsoil thickness, regrading angle, revegetation type and rehabilitation machinery types are entered for each feature as individual line items (Figure 2). Features can be separated into multiple line items based on profile differences, or rehabilitation requirements. The model uses equipment specifications and productivity curves from the 2017 Caterpillar Performance Handbook (Caterpillar 2017) combined with parameters such as fleet sizes, operator skill, and job efficiencies, to define the fleet and crew productivities and therefore the estimated cost for each of the rehabilitation line items. The cost basis can be third party rates, mine site rates, contractor rates or as defined by the regulator.

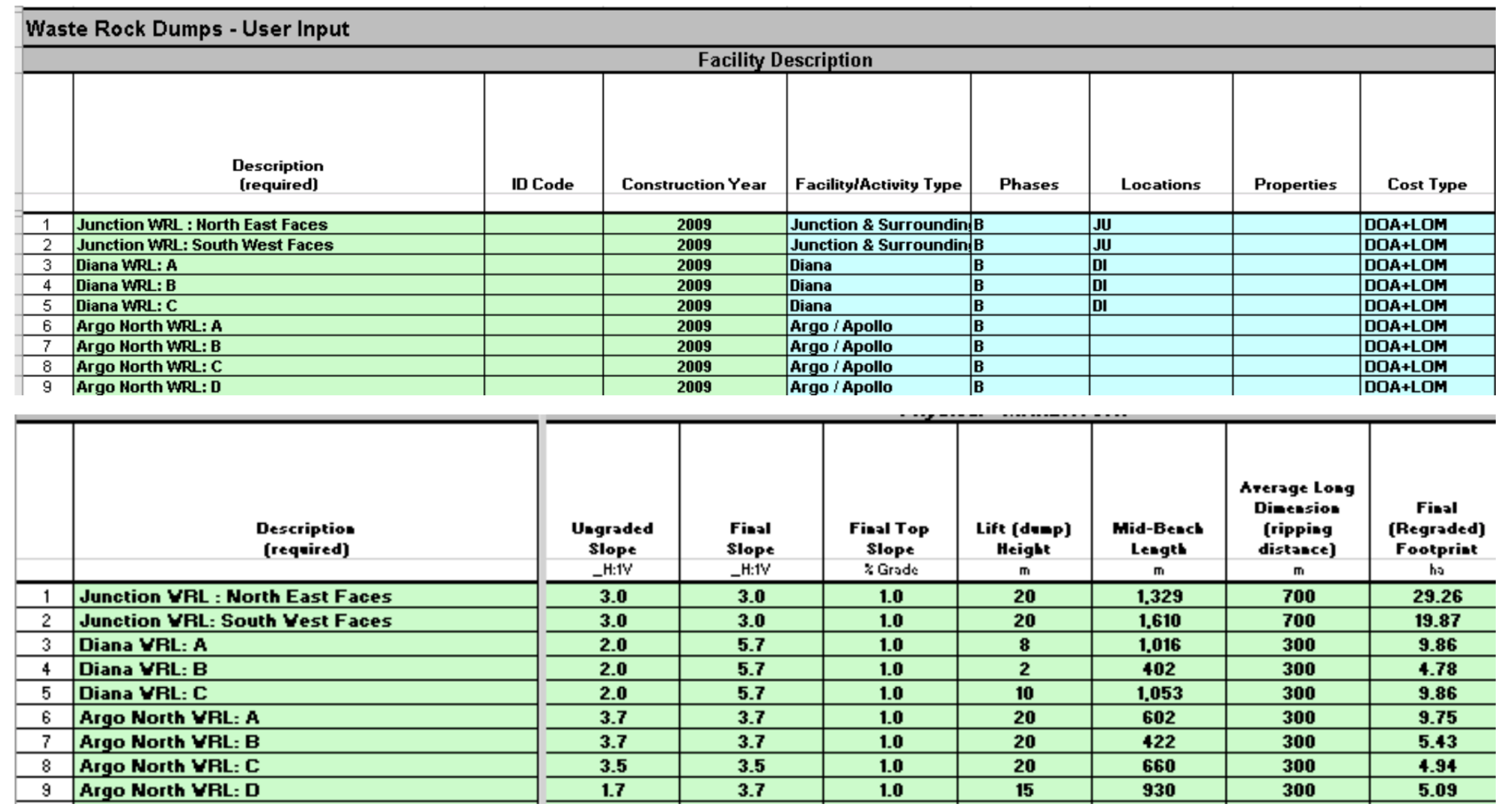

\section{Figure 2 Examples of feature input parameters}

A detailed scheduling worksheet is included in the latest version of SRCE (2.0), which allows users to schedule all closure rehabilitation works to be completed for each facility down to the activity level (i.e. regrading, cover placement, topsoil placement, revegetation). Each line item is assigned a work breakdown structure (WBS) code which are defined by the accounting team according to location or process (Figures 3 and 4). The WBS code structure enables the accounting and cash flow functions of the SRCE model.

\begin{tabular}{|c|c|c|c|}
\hline & Acct Code & Total Cost & LOM Cost \\
\hline & & AU\$ & \\
\hline TSF 3 & $8120 c^{* \star *} 1$ & 0 & 0 \\
\hline TSF 1 & $8120 c-\star \star \star 2$ & 0 & 0 \\
\hline TSF 2 & $8120 c^{-* * * 3}$ & 0 & 0 \\
\hline TSF 4 & $8120 c-{ }^{\star \star \star *} 4$ & 0 & 0 \\
\hline Heap Leach Pad & $8120 c--^{\star \star \star} 5$ & 0 & 0 \\
\hline Argo / Apollo & $8120 c--^{* \star *} 6$ & 0 & 0 \\
\hline Athena Complex & $8120 c-{ }^{\star \star \star} 7$ & 0 & 0 \\
\hline Beta/Hunt & $8120 c-{ }^{* \star \star *} 8$ & 0 & 0 \\
\hline Blue Lode & $8120 c^{* \star \star \star} 9$ & 0 & 0 \\
\hline
\end{tabular}

Figure 3 Closure costs grouped by work breakdown structure codes 


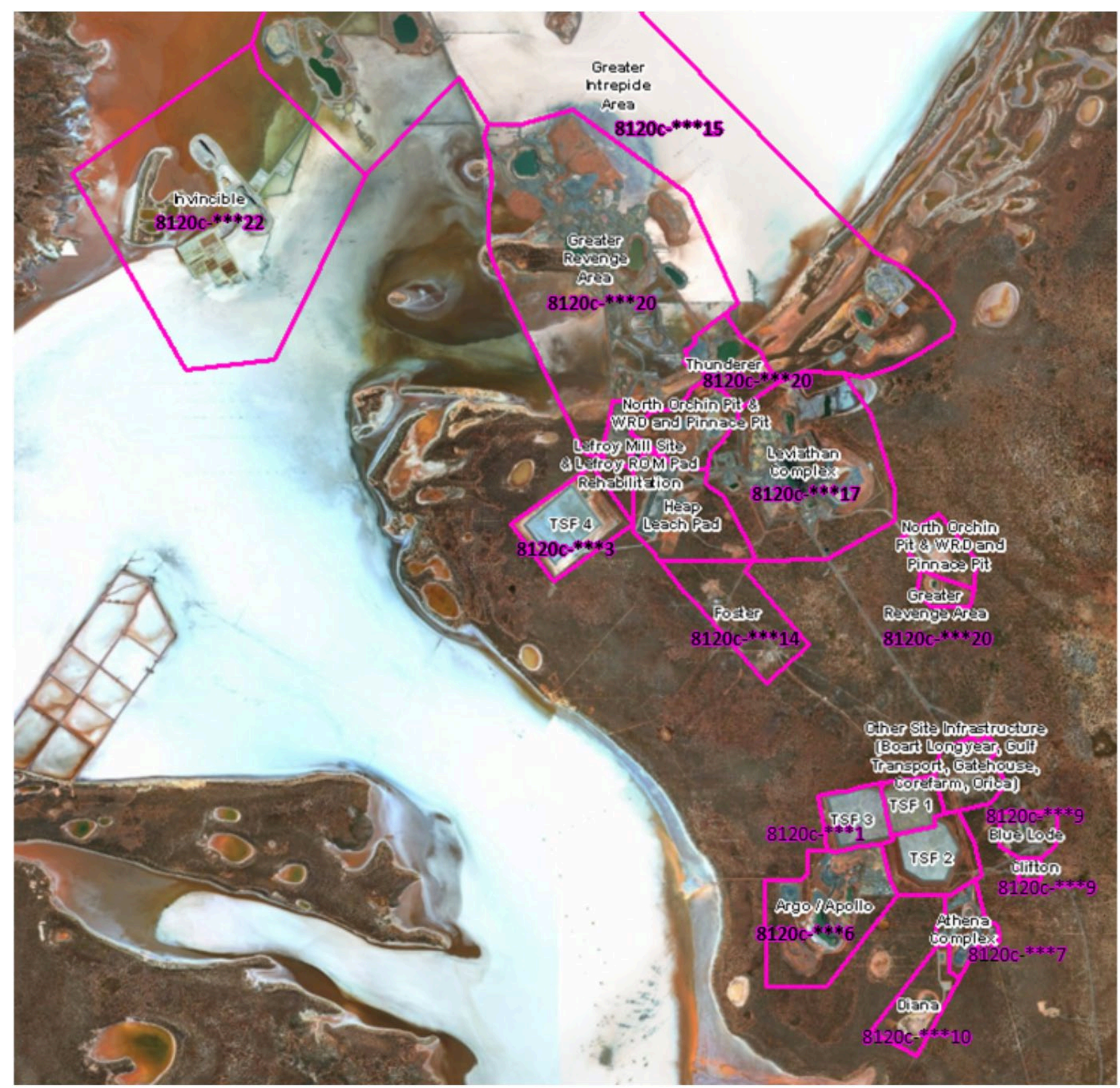

Figure 4 Work breakdown structure codes by location

Closure cost estimates can be filtered based on a number of parameters such as facility type, activity type, domain, location or rehabilitation schedule. SRCE 2.0 allows the user to define up to three filters (in addition to the WBS codes) and these can be assigned to each line item to allow the cost data and rehabilitation progress to be interrogated in several ways, dependent on site requirements. Once a schedule has been entered (Figure 5), a summarised cash flow output can be produced, which allows Gold Fields to track rehabilitation expenditure during the pre-closure, closure and post-closure periods.

As with all models, the SRCE is sensitive to the assumptions and limitations used to construct the cost estimate and the quality of data used. 

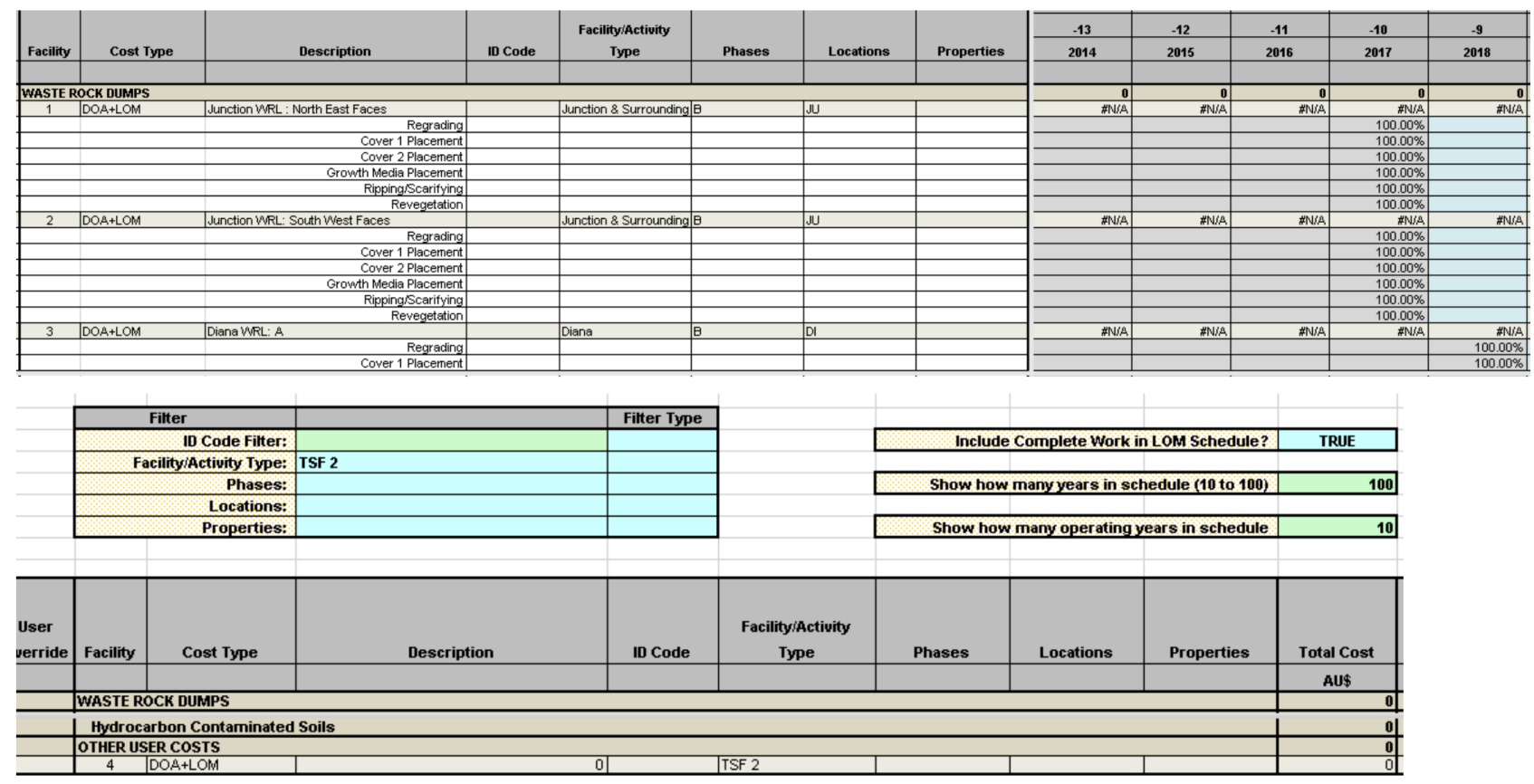

Figure 5 Scheduling worksheet and filter system

\subsection{Rehabilitation Management System}

An RMS was developed by Gold Fields to describe the process for planning, budgeting and progressive rehabilitation work. The purpose of the RMS is to consolidate, list and reference all the relevant approved documentation for rehabilitation. Gold Fields have developed the RMS to:

- Facilitate the management of rehabilitation issues.

- Ensure compliance with regulatory requirements.

- Improve environmental performance.

- Meet stakeholder and community expectations of St Ives.

The RMS workflow can be summarised as four main steps - planning, execution, monitoring, and reviewing/reporting - which mirrors the adaptive management framework of the MCP (Figure 6). The RMS applies to all areas that require rehabilitation by St Ives and the MCP determines the schedule of work.

The RMS starts with the triannual update of the MCP as per WA regulations. This MCP schedule defines the first stage of planning, which feeds into the development of the three-year Progressive Rehabilitation Plan (PRP) which then outlines the progressive rehabilitation budgeted to be completed onsite within the next three-year period. The PRP ensures that commitments made in the MCP clearly represent Gold Fields' operational, environmental and financial priorities for rehabilitation and uses the current mine plan to optimise waste rock in areas requiring rehabilitation. The plans are reviewed annually to ensure that Gold Fields is undertaking the most effective and efficient rehabilitation approach. 


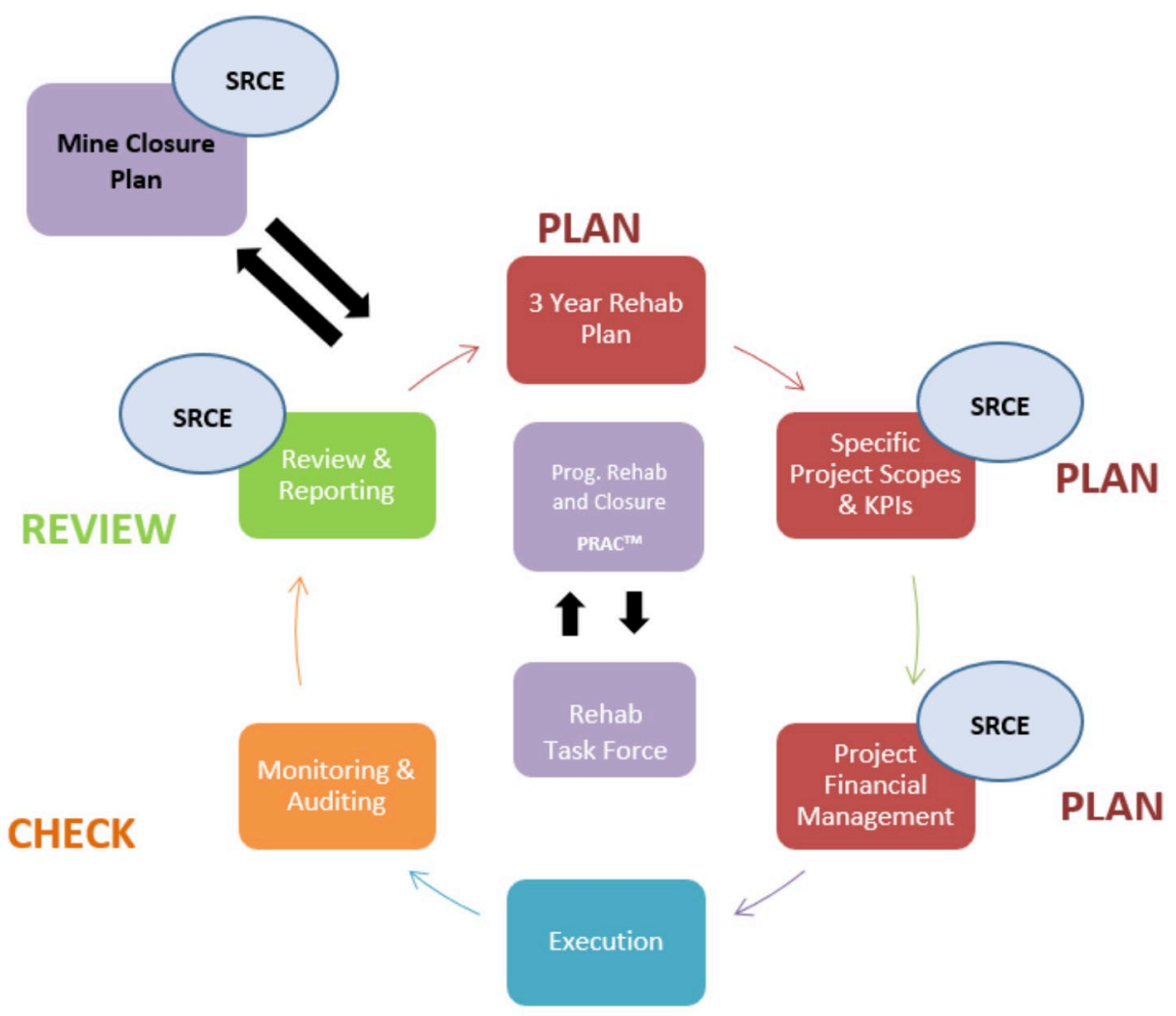

Figure 6 St Ives Rehabilitation Management System workflow

Funding for rehabilitation works is based on Gold Fields' commitments in the MCP and the closure cost allocated to each line item in the SRCE model associated with that work. A scope of works (SOW) is developed for each rehabilitation project as scheduled in the SRCE model which is defined by commitments in the MCP. The SOW tasks identified from the SRCE is used to obtain quotes from either external contractors or internal teams. Quotes are verified against the closure cost estimate in the SRCE model, and either challenged or accepted on a case-by-case basis (Table 1). Once quotes have been accepted, an authority for expenditure (AFE) is completed for the SOW for approval to access the funds.

Table 1 Provision check against quote

\begin{tabular}{lllll}
\hline $\begin{array}{l}\text { Task } \\
\text { number(s) }\end{array}$ & Location name (SRCE) & $\begin{array}{l}\text { WBS location } \\
\text { code }\end{array}$ & $\begin{array}{l}\text { Money remaining } \\
\text { on WBS code (AUD) }\end{array}$ & $\begin{array}{l}\text { Quotation } \\
\text { (AUD) }\end{array}$ \\
\hline $1,2,10$ & Junction and surrounding areas & $8120 c_{-* * * *-R 01}$ & \\
$3,5,7,8$ & Demolition & $8120 c^{* * * *}-$ R01 & \\
$4,6,9,11$ & Other site infrastructure & $8120 c^{* * * * *-R 01}$ & \\
12 & Exploration causeways & $8120 c^{* * * * *-R 01}$ & \\
\hline
\end{tabular}

Progressive rehabilitation is undertaken under the guidance of the SOW and within the AFE provision. These works are continually monitored, reviewed and reconciled to the MCP and the original closure cost estimate. Any variances are investigated and fed back into the planning process as required. 


\subsection{Integration of Standardized Reclamation Cost Estimator, Rehabilitation Management System and rehabilitation}

The SRCE is integral to the RMS at St Ives. The project financial management is aligned to the closure cost provision as calculated in the SRCE model. St Ives has utilised the WBS code structure and user defined filter functions of the SRCE model to allow alignment of closure cost estimates with the PRP. This allows the cost provision in the SRCE model to be the primary source of funding for progressive rehabilitation works onsite.

The St Ives chart of accounts is defined as the WBS account codes provided and approved by the Gold Fields' finance team. WBS codes are assigned to each line item in the SRCE model which is then used as a filter to summarise the cash flow estimates.

Three additional filters can be used dependent on site requirements and further levels of data interrogation. Gold Fields has used three different filters in their SRCE model to help define the rehabilitation workflow based on phases of work, domains and project locations. The schedule and cash flow summaries for a particular facility or progressive rehabilitation project can be investigated using these filters. These filters are continually added to as the site develops its ongoing PRPs. At St Ives the rehabilitation schedule has been included in the model based on the current MCP and PRP.

Each line item scheduled for rehabilitation is assigned a filter so that St Ives' rehabilitation team can quickly identify rehabilitation cost estimates and the required line items to include in the SOW. The SRCE is also used to track completed rehabilitation against the planned budget and WBS codes. The ability to isolate cost estimate data by line item means Gold Fields can decide whether to extract the cost of a single facility or an entire project. As the budget is already allocated for each WBS within the SRCE, the time it takes from planning to actual execution of rehabilitation is reduced.

In the case for Gold Fields, the MCP drives the schedule which identifies areas that require rehabilitation in the PRP. Typical works performed are shown in Table 2.

\section{Table 2 Closure provisioning inclusions}

\begin{tabular}{|c|c|}
\hline Item & Inclusions \\
\hline $\begin{array}{l}\text { Earthworks on waste rock } \\
\text { dumps, tailings storage facility, } \\
\text { safety berms, abandonment } \\
\text { bunds, underground openings }\end{array}$ & $\begin{array}{l}\text { All plant hire, personnel hire, supervision, regrading, ripping, } \\
\text { seeding, topsoil, dozing, revegetation, backfilling of underground } \\
\text { openings }\end{array}$ \\
\hline Generic hauling & Coarse fill, fine-grained fill, growth media \\
\hline Closure planning & $\begin{array}{l}\text { Annual studies, compliance reporting, rehabilitation health studies } \\
\text { (only on specified years for specified projects) }\end{array}$ \\
\hline Drainage & Toe drain construction on landforms \\
\hline Process ponds & Removal and backfilling and associated labour and supervision \\
\hline Industrial infrastructure removal & Equipment hire, labour and supervision (mechanical demolition only) \\
\hline Yard earthworks & $\begin{array}{l}\text { All plant hire, personnel hire, supervision, regrading, ripping, } \\
\text { seeding, topsoil, dozing, revegetation, backfilling of underground } \\
\text { openings }\end{array}$ \\
\hline Monitoring well closure & Removal, filling and associated labour hire \\
\hline $\begin{array}{l}\text { Solid offsite waste disposal } \\
\text { (non-hazardous) }\end{array}$ & $\begin{array}{l}\text { Removal of miscellaneous waste across the operation (i.e. pipes, } \\
\text { concrete, etc.) }\end{array}$ \\
\hline Administration for lease holdings & $\begin{array}{l}\text { Insurances for lease holder, ongoing electricity, water and } \\
\text { telecommunications requirements }\end{array}$ \\
\hline Closure monitoring costs & Laboratory analysis, equipment purchases and labour \\
\hline Miscellaneous removal & Buried infrastructure removal, electrical substation removal, etc. \\
\hline
\end{tabular}




\section{$3 \quad$ Results}

The SRCE model is the primary planning, scoping and budgeting tool for mine closure activities at St Ives. Using the SRCE as previously described allows mine closure works to be easily planned and budgeted as relevant line items can be quickly located using the system of filters set-up by SRK and Gold Fields.

The ability to correlate closure works that have been scheduled in the MCP to line items in the SRCE allows a SOW to be generated simply and quickly. Planned works are presented and agreed by the rehabilitation task force so allocation and timing of expenditure is transparent and well understood, which creates an efficient and effective workflow.

Using SRCE in this way has enabled Gold Fields to review and reconcile the cost estimation calculated by the SRCE model to actual costs on site. Where differences were identified during progressive rehabilitation, site investigations were undertaken to identify the source of the error and this information was used to adjust the closure methods used in the SRCE model to align more closely with actual data.

Gold Fields found that actual costs for bulk earthworks when compared to the SRCE cost estimate were typically within $10-20 \%$. There were notable exceptions where this wasn't the case, namely the placement of abandonment bunds and battering slopes. It was found that bund construction costs were underestimated by the SRCE model as Gold Fields uses a different construction method than the standard calculation in the SRCE. Once this was identified, the volumes were calculated based on actual construction designs for the site for incorporation in the SRCE model. The external calculations used are referenced in the model's User Sheets for auditing purposes.

The RMS review process also identified that during the cover construction at the Bellerophon waste rock dump, $30 \%$ more topsoil material was required on the oxide slopes to meet the MCP commitments due to higher than anticipated topsoil compaction rates. This observation was reconciled against the provision process by increasing the volumes required for all remaining waste rock dumps with oxide slopes. Because of the built-in flexibility of the SRCE model, site-specific volume calculations can be used and applied to all similar tasks.

The most important aspect to this process is the ability to link the closure cost estimate model to work conducted on the ground. The SRCE enables mine closure planning, scheduling and budgeting to be integrated into the mine plan and mine operations and the results from the ground are used to continually improve the accuracy of the closure cost estimation and makes simple and transparent workflows possible onsite. Grant \& Lacy (2016) describe effective integration as requiring a combination of technology, process and people which is exemplified by Gold Fields' RMS.

An example of this is the integration of the three-year PRP schedule which highlighted opportunities to integrate mining with progressive rehabilitation works. Gold Fields utilised the opportunity to directly place waste as a cover onto rehabilitation areas, reducing the need for double-handling and minimising closure costs. Gold Fields has been able to demonstrate significant cost savings by utilising the mining fleet to complete proposed progressive rehabilitation projects. While the use of the available mining fleet in this way has incurred incremental increases to operational mining costs, Gold Fields has been able to demonstrate the business case for overall cost reduction by integrating the mine operations and the SRCE for rehabilitation planning.

St Ives also uses the SRCE internally for due diligence evaluation when considering additional mining opportunities during pre-feasibility and feasibility assessments. Auditability and defensibility are important for Gold Fields. The SRCE closure cost provision at Gold Fields uses third party contractor rates which are updated annually and reviewed by an independent auditor. This ensures the provision of a robust and auditable closure cost estimate. The SRCE model is audited internally on an annual basis, and externally by independent auditors every three years. The SRCE model allows certification for financial accounting requirements and is also incorporated as part of the Commonwealth Fraud Control Framework. 


\section{Conclusion}

The SRCE model is an internationally and widely used tool for closure cost estimation, primarily for LOM, PER and financial assurance requirements. Gold Fields' St Ives gold mining operations is a large mine complex, with 19 satellite open cut and underground mines at various stages of rehabilitation and associated waste dumps, processing, water management, transport and administrative infrastructure.

In addition to annual provisioning of mine closure costs, Gold Fields has utilised the SRCE model as the primary planning and budgeting tool for closure activities using site-specific filters for ease of use. The SRCE model is used to identify tasks to prepare a SOW for tendering to obtain quotes for scheduled closure activities. Quotes are compared to the SRCE cost estimate for validation. The SRCE cost estimates are also compared to actual data from progressive rehabilitation and where discrepancies are identified, these are incorporated back into the SRCE model to improve future planning and accounting accuracy. The integration of mine closure planning with operations, and the continual improvement of the cost model as a result of this integration, are arguably the most important aspects of this process.

Additional uses for the SRCE include due diligence evaluations for pre-feasibility and feasibility assessments, auditability of certification for financial accounting requirements, and the SRCE model is also audited as part of the Commonwealth Fraud Control Framework.

The integration of mine closure planning and operations through a continual adaptive cycle of cost estimation, scheduling of progressive rehabilitation work, and review and refinement of cost assumptions to enable more accurate closure cost estimation mirrors current international best practice (DIIS 2016; ICMM 2019).

\section{Acknowledgement}

SRK acknowledges the assistance of St Ives and Gold Fields in preparing this paper.

\section{References}

APEC Mining Task Force 2018, Mine Closure Checklist for Governments, Asia-Pacific Economic Cooperation, Singapore.

Caterpillar 2017, Caterpillar Performance Handbook, 47th edn, Peoria.

Department of Industry, Innovation and Science (DIIS) 2016, Mine Closure - Leading Practice Sustainable Development Program for the Mining Industry, Commonwealth of Australia, Canberra.

Dodd, CD, Lee, F \& Marshall, RC 2006, 'Mine closure planning - the auction process as an option to assist with financing closure', in $A B$ Fourie \& M Tibbett (eds), Proceedings of the First International Seminar on Mine Closure, Australian Centre for Geomechanics, Perth, pp. 509-512.

Drebenstedt, C 2006, 'Financial valuation of mine closure alternatives', in AB Fourie \& M Tibbett (eds), Proceedings of the First International Seminar on Mine Closure, Australian Centre for Geomechanics, Perth, pp. 499-508.

Gold Fields Ltd 2011, Rehabilitation Management System, St Ives Gold Mine, Western Australia.

Grant, CD \& Lacy, HWB 2016, 'Developing Anglo American's integrated closure planning system requires people, process and technology working together', in AB Fourie \& M Tibbett (eds), Proceedings of the 11th International Conference on Mine Closure, Australian Centre for Geomechanics, Perth, pp. 581-594.

International Council on Mining and Metals (ICMM) 2019, Integrated Mine Closure Good Practice Guide, 2nd edn, International Council on Mining and Metals, London.

Morrison-Saunders, A, McHenry, MP, Sequeira, AR, Gorey, P, Mtegha, H \& Doepel, D 2016, 'Integrating mine closure planning with environmental impact assessment: challenges and opportunities drawn from African and Australian practice', Impact Assessment and Project Appraisal, vol. 34, no. 2, pp. 117-128, https://doi.org/10.1080/14615517.2016.1176407

Nehring, M \& Cheng, X 2016, 'An investigation into the impact of mine closure and its associated cost on life of mine planning and resource recovery', Journal of Cleaner Production, vol. 127, pp. 228-239, https://doi.org/10.1016/j.jclepro.2016.03.162

Pierce, GL \& Wen, ME 2006, 'Planning for in-perpetuity mine closure costs', in AB Fourie \& M Tibbett (eds), Proceedings of the First International Seminar on Mine Closure, Australian Centre for Geomechanics, Perth, pp. 487-492.

Steadman, A \& Green, KP 2018, Fraser Institute Annual Survey of Mining Companies 2018, Fraser Institute, viewed 1 April 2019, http://www.fraserinstitute.org

Watson, AH 2006, 'Better closure cost estimates', in AB Fourie \& M Tibbett (eds), Proceedings of the First International Seminar on Mine Closure, Australian Centre for Geomechanics, Perth, pp. 493-497.

Western Australian Environmental Protection Authority 2015, Guidelines for Preparing Mine Closure Plans, Perth.

Wiid, GJ 2006, 'The role of closure planning in the environmental and financial reporting processes for mining operations', in $A B$ Fourie \& M Tibbett (eds), Proceedings of the First International Seminar on Mine Closure, Australian Centre for Geomechanics, Perth, pp. 513-524. 